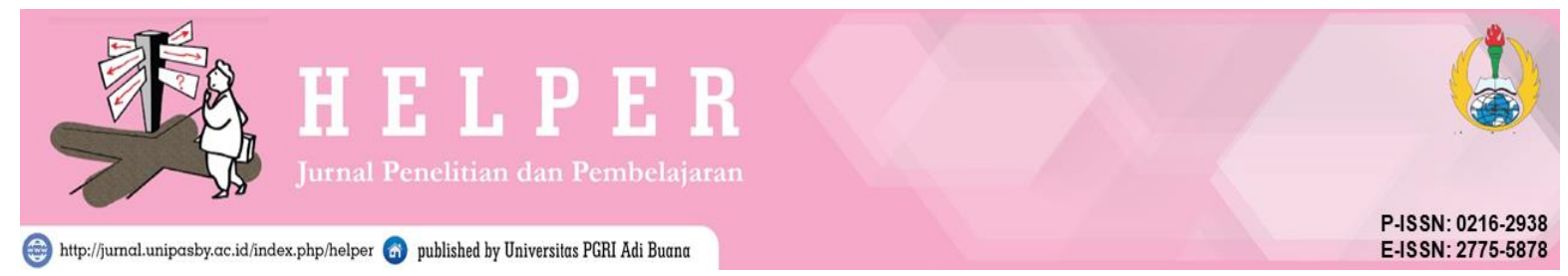

Vol. 38 No. 1 (2021)

\title{
EFEKTIVITAS LAYANAN INFORMASI DALAM BIMBINGAN KELOMPOK DENGAN MEDIA TIK TOK UNTUK MENINGKATKAN SELF CONCEPT SISWA
}

\author{
Apriliani Savira Amadhea \\ Bimbingan dan Konseling, Fakultas Pedagogi \& Psikologi, \\ Universitas PGRI Adi Buana Surabaya \\ aprilianisvr@gmail.com \\ Maghfirotul Lathifah, S.Pd., M.Pd. \\ Bimbingan dan Konseling, Fakultas Pedagogi \& Psikologi, \\ Universitas PGRI Adi Buana Surabaya \\ maghfirotul@unipasby.ac.id
}

\begin{abstract}
Abstrak
Self concept merupakan pandangan diri seseorang,bagaimana orang tersebut memahami dirinya. Banyak siswa yang mengalami Self Concept rendah yang ditemukan di SMP 1 Taman, sehingga untuk meningkatkan Self Concept menggunakan layanan informasi dalam bimbingan kelompok dengan media Tik Tok. Tujuan penelitian ini adalah untuk mengetahui keefektifan layanan informasi dalam bimbingan kelompok dengan media tik tok untuk meningkatkan self concept siswa. Desain penelitian menggunakan pre-experimental pre test-post test design, teknik dalam pengambilan sampel menggunakan purposive sampel yang berjumlah 5 siswa VII. Metode pengumpulan data yang digunakan yaitu skala pengukuran dengan menggunakan skala likert sedangkan teknik analisis data yang digunakan uji wiloxon statistik non parametrik. Hasil penelitian menunjukan adanya efektivitas layananan informasi dalam bimbingan kelompok dengan media tik tok untuk meningkatkan self concept siswa dengan hasil self concept siswa sebesar 52,6\% termasuk kategori tinggi. Artinya ada perbedaan yang signifikan pre-test dan post-test. Hal ini dapat simpulkan layanan informasi dalam bimbingan kelompok dengan media Tik tok efektif dapat meningkatkan Self concept siswa.
\end{abstract}

Kata Kunci: Self Concept, bimbingan kelompok, tik tok

\begin{abstract}
Abstact
Self concept is a person's view of how that person understands himself. Many students experience low self-concepts found in SMP 1 Taman, so to improve their self-concept, they use information services in group guidance with Tik Tok media. The purpose of this study was to determine the effectiveness of information services in group guidance with Tik Tok media to improve students' self-concepts. The research design used pre-experimental pre-test-post-test design, the technique of taking the sample used a purposive sample, amounting to 5 students VII. The data collection method used is the measurement scale using the Likert scale while the data analysis technique used is the non-parametric statistical Wiloxon test. The
\end{abstract}


results showed the effectiveness of information services in group guidance with Tik Tok media to improve students 'self-concepts with $52.6 \%$ of students' selfconcepts, including the high category. This means that there is a significant difference in pre-test and post-test. This can conclude that information services in group guidance with Tik Tok media can effectively improve students' selfconcept.

Keywords: Self Concept, group guidance, tick tock

\section{PENDAHULUAN}

Pada dasarnya seorang remaja mampu memahami dirinya, maka remaja remaja tersebut mampu beradaptasi dan berinteraksi dengan lingkungannya, oleh karena itu perkembangan remaja dipengaruhi oleh kondisi disekitarnya. Self Concept pada remaja terbentuk dari pengalaman individu dalam berhubungan dengan individu lain. Sehingga Self Concept yang diharapkan merupakan Self Concept yang positif yang sangat penting bagi kehidupan remaja.

Self Concept merupakan merupakan pandangan diri seseorang,bagaimana orang tersebut memahami dirinya sendiri (Ting, 2019). Pada kenyataannya hanya sedikit remaja yang memiliki Self Concept yang positif. banyak remaja yang belum mampu mengidentifikasi dirinya sehingga ikutikutan dengan teman sebayanya.

Berdasarkan hasil pengamatan yang dilakukan oleh peneliti ditemukan adanya Self Concept yang rendah pada diri siswa SMP N 1 TAMAN. Hal ini di tunjukan adanya siswa cenderung kurang aktif bertanya pada saat pembelajaran daring, tidak percaya diri untuk memperlihatkan wajahnya di kamera saat pembelajaran daring, siswa tidak senang membaca, merasa malu sebab memiliki nilai yang rendah, tidak pernah mematuhi tata tertib sekolah, siswa tidak pernah mengikuti pembelajaran daring karena merasa malu memiliki handphone yang tidak upgrade dengan temannya, saat pembelajaran daring siswa tidak memakai seragam sekolah karena merasa tidak keren.

Apabila siswa tidak segera di atasi, maka menimbulkan dampak yang cukup besar bagi kehidupan. Siswa akan senantiasa memandang dirinya lemah, tidak bedaya, gagal, tidak menarik (Syanti,gultom, 2017). Sedangkan Self Concept dapat dipengaruhi oleh faktor kegagalan, keadaan fisik, tuntutan orang tua, kondisi keluarga, ras dan kulit (Tiffany, 2017).

Dari penjelasan diatas untuk meningkatkan self concept siswa dapat dilakukan dengan layanan informasi dalam bimbingan kelompok dengan menggunakan media tik tok. Melalui bimbingan kelompok, konselor memberikan pendekatan kepada siswa dengan media tik tok sehingga dapat membantu memecahkan masalah yang dialami siswa.

Tik Tok adalah video yang terpopuler di media sosial saat ini dengan durasi pendek sehingga dapat mengembangkan ekspresi dan kreativitasnya, sehingga konselor lebih mudah membantu siswa dengan proses bimbingan kelompok. 
Efektivitas Layanan Informasi Dalam Bimbingan Kelompok Dengan Media Tik Tok Untuk Meningkatkan Self Concept Siswa

Dapat simpulakan bahwa peneliti menggunakan layanan informasi dalam bimbingan kelompok dengan media tik tok untuk meningkatkan self concept siswa.

\section{METODE PENELITIAN}

Pre-experimental with One Group Pre-Test Post-Test Design adalah metode yang digunakan dalam penelitian ini. Desain penelitian ini pemberian treatment dalam suatu kelompok (sugiyono, 2010)

Gambar 1. Rancangan penelitian One Group Pre-Test Post-Test Design

\begin{tabular}{|ll|}
\hline $\mathrm{T}_{1}$ & $\mathrm{X}_{\mathrm{t}}$ \\
\hline
\end{tabular}

Keterangan:

$\mathrm{O}_{1}$ : Pengukuran Pre-test untuk meningkatkan self Concept pada siswa sebelum dilakukan layanan informasi dengan menggunakan media Tik Tok dalam bimbingan kelompok.

$\mathrm{X}_{\mathrm{t}}$ : Pelaksanaan layanan informasi dalam bimbingan kelompok dengan media Tik Tok

$\mathrm{O}_{2}$ : Pengukuran Post-test untuk mengukur self Concept siswa pada sampel setelah dilakukan layanan informasi dengan menggunakan media Tik Tok dalam bimbingan kelompok.

Berdasarkan uraian diatas, maka kelompok experiment merupakan kelompok yang diberikan treatment, dalam perlakuannya berupa bimbingan kelompok dengan menayangkan video tik tok. Treatment bimbingan kelompok dengan menayangkan video tik tok yang diberikan sebanyak 6 kali pertemuan.

Sehingga terdapat 5 subjek di kelas VII di SMPN 1 TAMAN, dengan 5 subjek yang memiliki self concept rendah. Untuk mendapatkan subjek penelitian berdasarkan hasil pre-test pada 3 kelas A (30), B (30), C (32) siswa dan mengambil 5 siswa yang mempunyai self concept rendah. Dalam pengambilan sampel, peneliti menggunakan purposive sampling. Purposive sampling adalah teknik pengambilan sampel dengan kriteria-kriteria tertentu. Berdasakan kriteria yang memiliki self concept dengan katagori rendah yang dipilih oleh peneliti.

Metode pengumpulan data/instrument data penelitian ini dilakukan dengan cara mengerjakan lembar skala pengukuran. Peneliti menggunakan skala pengukuran sebagai instrument pengumpulan data sebagai acuan untuk menentukan panjang pendeknya interval yang ada pada alat ukur sehingga digunakan pengukuran akan menghasilkan data. Skala pengukuran tersebut dirancang menggunakan model skala likert dengan 4 pilihan, yaitu sangat setuju (SS), setuju (S), tidak setuju (TS), dan sangat tidak setuju (STS). Prosedur pengembangan skala pengukuran ini, adalaha: 1) mendefinisikan variabel peelitian secara operasional,yaitu variabel self conept. 2) mengembangkan blue print skala self concept. 3) menyusun butir item skala pengukuran. 4) melakukan telah ahli sebagai acuan meriview 
Efektivitas Layanan Informasi Dalam Bimbingan Kelompok Dengan Media Tik Tok Untuk Meningkatkan Self Concept Siswa

skala pengukuran. 5) melakukan uji coba try out untuk menemukan validitas skala pengukuran perilaku self concept siswa berdasarkan ko efesien kolerasi butir total Alpha Cronbach.

Pengujian penelitian ini menggunakan teknik analisis data Uji Wilcoxon Statistik non parametrik karena sampel yang digunakan relative kecil. Pendekatan statistik uji wilxocon W+ menggunakan distribusi normal dapat dilakukan jika $n \leq 25$ dengan menggunakan uji stastistik.

\section{HASIL PENELITIAN}

Sebelum melaksanakan treatment layanan bimbingan kelompok, peneliti memberikan pre test kepada siswa 92 siswa kelas VII A,B,C di SMPN 1 TAMAN.

Tabel 2. Skor Hasil Pre-test sangat rendah

\begin{tabular}{llll}
\hline No & Responden & Skor & Kategori \\
\hline 1 & PSW & 30 & Rendah \\
\hline 2 & RS & 32 & Rendah \\
\hline 3 & SINH & 33 & Rendah \\
\hline 4 & NS & 34 & Rendah \\
\hline 5 & SAA & 35 & Rendah \\
\hline
\end{tabular}

Setelah pemberian treatment peneliti memberikan post test kepada siswa yang memiliki self concept rendah untuk mengetahui apakah ada peningkatan self concept siswa.

Tabel 3. Hasil Skor post-test self concept siswa

\begin{tabular}{|c|c|c|c|}
\hline No & Responden & Skor & Kategori \\
\hline 1 & PSW & 51 & Tinggi \\
\hline 2 & RS & 53 & Tinggi \\
\hline 3 & SINH & 53 & Tinggi \\
\hline 4 & NS & 54 & Tinggi \\
\hline 5 & SAA & 52 & Tinggi \\
\hline
\end{tabular}

Tabel pada $2 \& 3$ hasil perlakuan siswa yang memiliki self Concept rendah dari pre test dan pos test dengan perbandingan sebagai berikut:

Tabel 4. Hasil Perbandingan Pre-test dan Post-test self Concept siswa SMP 


\begin{tabular}{|c|c|c|c|c|c|c|}
\hline No & $\begin{array}{l}\text { Nama } \\
\text { Siswa }\end{array}$ & $\begin{array}{l}\text { Pre } \\
\text { Test } \\
(\mathbf{X})\end{array}$ & Kategori & $\begin{array}{l}\text { Post } \\
\text { Test } \\
\text { (Y) }\end{array}$ & $\begin{array}{l}\text { Kategor } \\
\text { i }\end{array}$ & $\begin{array}{l}\text { Perbedaa } \\
\text { n Skor }\end{array}$ \\
\hline 1 & PSW & 30 & Rendah & 51 & Tinggi & 21 \\
\hline 2 & RS & 32 & Rendah & 53 & Tinggi & 21 \\
\hline 3 & SINH & 33 & Rendah & 53 & Tinggi & 20 \\
\hline 4 & NS & 34 & Rendah & 54 & Tinggi & 20 \\
\hline 5 & SAA & 35 & Rendah & 52 & Tinggi & 17 \\
\hline Rata & & 32,8 & & 52,6 & 19,8 & \\
\hline
\end{tabular}

Pada tabel 4 dijelaskan bahwa adanya siswa yang memiliki self concept masuk dalam kategori rendah ketika pre test mencapai rata-rata 32,8\%. Setelah diberikan perlakuan post test hasilnya menjadi 52,6\% dengan rata-rata peningkatan 19,8\%. Berdasarkan hasil tersebut,maka self concept pada siswa SMPN 1 TAMAN mengalami peningkatan ketika diberikan perlakuan bimbingan kelompok dengan media tik tok.

\section{PEMBAHASAN}

Self Concept merupakan merupakan pandangan diri seseorang,bagaimana orang tersebut memahami dirinya sendiri (Ting, 2019). Pada kenyataannya hanya sedikit remaja yang memiliki Self Concept yang positif. banyak remaja yang belum mampu mengidentifikasi dirinya sehingga ikutikutan dengan teman sebayanya. Penelitian ini di lakukan (Annisa Apriliyanti, Mudjiran, 2016), Jurusan pendididkan Konseling. bahwa terdapat hubungan yang signifikan antara Self Concept dengan tingkah laku sosial siswa. SMK Negeri 6 Padang, yakni semakin tinggi Self Concept siswa maka semakin baik pula tingkah laku sosial siswa demikian sebaliknya semakin rendah Self Concept siswa maka semakin rendah pula tingkah laku sosial siswa. siswa yang memiliki karakteristik Self Concept negatif siswa selalu sensitif terhadap kritikan orang lain, mempuyai sikap yang berlebihan dalam tindakan, selalu beranggapan bahwa orang lain memandang dirinya negatif, marasa senang mengeritik orang lain, kurangnya berinteraksi dengan orang lain (Timdokter, 2013).

Media tik tok adalah aplikasi video yang berdurasi pendek yang digunakan untuk membuat komunitas hiburan online, dengan pembuatannya yang memiliki jenis alat, filter, efek dan menampilkan minat mereka miliki seperti menari, menyanyi, sinkronasi bibir serta diiringi oleh musik (Zhang, 2020).

Bimbingan kelompok merupakan Bimbingan kelompok adalah proses bantuan konselor kepada konseli melalui usaha siswa itu sendiri agar dapat membantu dan mengembangkan 
kebahagiaan pribadi dan sosial siswa (RITCHIE, n.d.). peneliti memnggunakan bimbingan kelompok dengan media tik tok dengan tahap-tahap sebagai berikut:

I. Tahapan pembentukan Kelompok ,merupakan tahap kegiatan awal dalam kegiatan bimbingan kelompok, kegiatan-kegiatan pada tahap awal meliputi:

1. Pengenalan atau pengungkapan tujuan

2. Terbangunnya kebersamaan

3. Grup tertutup yaitu tidak ada anggota baru yang boleh masuk dalam pelaksanaan treatment

4. Daring google meet

5. Durasi setiap pertemuan yaitu maksimal 45 menit

6. Beberapa teknik pada tahap awal meliputi menanyakan kabar, penerapan tanggapan atau respon, serta penerapan ice breaking.

7. Dalam kelompok ini terdiri dari siswa yang mendapatkan kategori self Concept rendah.

II. Tahapan orientasi dan explorasi yaitu menentukan struktur kelompok, berkenalan dengan sesama anggota kelompok, membangun kepercayaan kemudian membangun hubungan baik: terciptanya susunan yang baik antara konselor dan konseli. Kegiatan-kegiatan yang ada dalam membangun hubungan baik ini adalah membuat kontrak pelaksanaan dan pembahasan tujuan bimbingan kelompok.

1. menjelaskan tanggung jawab kelompok

2. respon terhadap anggota kelompok yang lain

3. anggota kelompok saling berkerjasama

4. keputusan kelompok sejauh mungkin memuaskan semua anggota kelompok dan tidak hanya memenuhi keinginan anggota mayoritas

5. masalah yang timbul harus dihadapi

III. Tahapan transisi yaitu tahapan yang menantang, pada tahap ini para anggota menghadapi kecemasan, konflik, dan kegelisahan dalam kelompok.

1. Penjelasan konflik dapat merupakan kekuatan yang positif

2. Memberi bantuan dan keyakinan terhadap ungkapan konflik secara terbuka

3. Mendengarkan aktif

4. Merespon terhadap perasaan-perasaan

IV. Tahapan pembahasan merupakan tahapan inti dimana kegiatan materi layanan responsif menggunakan media Tik Tok ditampilkan. 
Kegiatan dalam tahapan ini yaitu:

1. Pembahasan dan mengemukakan permasalahan

2. Pemilihan masalah self concept

3. Pembahasan masalah self concept dan pemberian bimbingan kelompok dengan menggunakan media Tik Tok

4. Pembahasan hasil dari masalah Self Concept

V. Tahapan Evaluasi dan pengakhiran merupakan tahap evaluasi dari kegiatan layanan dalam pertemuan yang sudah dilakukan. Tahapan pengakhiran meliputi:

1. Frekuensi pertemuan: kegiatan ini lebih difokuskan ada hasil yang didapatkan pada pertemuan kegiatan.

2. Pembahasan keberhasilan yang diharapkan pada kemampuan dalam menerapkan.

3. saling berdiskusi mengenai kesan terhadap masing-masing anggota pada waktu pertama kali bertemu.

Layanan informasi dalam bimbingan kelompok dengan video tik tok dapat meningkatkan self concept siswa pada tahap ini, pelaksanaan bimbingan kelompok dilaksanakan sebanyak 6 kali pertemuan dengan 3 kali treatment yaitu:

a. Pre-test

Pre-test dilaksanakan pada tanggal 26 januari 2021, melalui link google from yang dibagikan via watsapp

\section{b. Treatment}

1. Treatment pertama dilaksanakan pada tanggal 3 februari melalui link google meet. tahap awal konselor membuka salam,berdoa dan menanyakan kesiapan konseli, konselor menjelaskan peraturan dan kode etik dalam bimbingan kelompok. konselor menjelaskan topik yang akan dibahas "kurang percaya diri" dan memperlihatkan video tik tok kepada konseli, setelah itu konselor meminta untuk mengisi lembar refleksi. Konselor memberikan evaluasi dan menyimpulkan kegiatan yang telah dilakukan, selanjutnya konselor menutup kegiatan dengan doa dan membuat perjanjian pertemuan selanjutnya.

2. Treatment kedua dilaksanakan pada tanggal 4 februari melalui link google meet. tahap awal konselor membuka salam,berdoa dan menanyakan kesiapan konseli, konselor menjelaskan peraturan dan kode etik dalam bimbingan kelompok. konselor menjelaska topik yang akan dibahas "kurang kedisiplinan" dan memperlihatkan video tik tok kepada konseli, setelah itu konselor meminta untuk mengisi lembar refleksi. Konselor 
memberikan evaluasi dan menyimpulkan kegiatan yang telah dilakukan, selanjutnya konselor menutup kegiatan dengan doa.

3. Treatment ketiga dilaksanakan pada tanggal 5 februari melalui link google meet. tahap awal konselor membuka salam,berdoa dan menanyakan kesiapan konseli, konselor menjelaskan peraturan dan kode etik dalam bimbingan kelompok. konselor menjelaska topik yang akan dibahas "carajitu belajar efektif" dan memperlihatkan video tik tok kepada konseli, setelah itu konselor meminta untuk mengisi lembar refleksi. Konselor memberikan evaluasi dan menyimpulkan kegiatan yang telah dilakukan, selanjutnya konselor menutup kegiatan dengan doa.

c. Post-test

Pos-test dilaksanakan 8 februari melalui via google from yang dibagikan lewat watsapp

Berdasarkan hasil analisis uji wilcoxon pada tabel test statistics diatas diketahui Asymp. Sig (2-tailed) bernilai 0,041. Karena nilai 0,041 lebih kecil dari < 0,05, maka dapat disimpulkan bahwa Ha diterima. Artinya ada perbedaan antara self Concept siswa untuk pre-test dan post-test, sehingga dapat disimpulkan bahwa ada efektivitas penggunaan media Tik Tok dalam bimbingan kelompok untuk meningkatkan self concept siswa SMP.

\section{KESIMPULAN}

Berdasarkan hasil pre test dan post test pada self concept siswa SMPN 1 TAMAN, maka disimpulkan bahwa "layanan informasi dalam bimbingan kelompok dengan video tik tok ada efektivitas untuk meningkatkan Self Concept" maka dapat disimpulkan setelah pemberian treatment layanan bimbingan kelompok dengan video tik toksangatlah berpengaruh untuk meningkatkan self concept pada siswa dengan kategori rendah menjadi tingga. Peningkatan antara pre-test mencapai rata-rata $32,8 \%$. Setelah diberikan perlakuan post-test hasilnya menjadi 52,6\% dengan rata-rata peningkatan mencapai $19,8 \%$.

Ada perbedan yang signifikan antara hasil pre-test dan post-test. Sehingga layanan informasi dalam bimbingan kelompok dengan media tik tok ada efektivitas untuk meningkatkan self concept. Sehingga bagi peneliti selanjutnya, yang akan melakukan penelitian mengenai Self Concept. dapat melakukan penelitian dijenjang pendidikan yang berbeda dengan jenis layanan dan media yang berbeda.

\section{DAFTAR PUSTAKA}

Annisa Apriliyanti, Mudjiran, M. R. (2016). Hubungan Konsep Diri Siswa dengan Tingkah Laku Sosial Siswa. Jurnal EDUCATIO Jurnal Pendidikan Indonesia, 2(2), 25-29. 
Efektivitas Layanan Informasi Dalam Bimbingan Kelompok Dengan Media Tik Tok Untuk Meningkatkan Self Concept Siswa

RITCHIE, T. D. (n.d.). Guidance And Counseling.

sugiyono. (2010). Metode Penelitian Pendidikan Pendekatan Kuantitatif, kualitatif, dan R\&D. Bandung: Alfabeta.

Syanti,gultom, A. m. (2017). http://bkpsdmd.babelprov.go.id (hal. 1-3).

Timdokter. (2013). karakteristik konsep dri negatif dan postif.

Ting, H. (2019). Self-Concept and School Performance. Journal of Chemical Information and Modeling, 53(9), 1689-1699.

Zhang, Z. (2020). Infrastructuralization of Tik Tok: transformation, power relationships, and platformization of video entertainment in China. Media, Culture and Society. https://doi.org/10.1177/0163443720939452 